\title{
Pesquisa de Recursos de Visualização 3D a partir da Avaliação do Programa Ester de Projeção ESTEREOGRÁFICA
}

\author{
Giovanni Amaral Guimarães*, Celso Dal Ré Carneiro
}

\begin{abstract}
Resumo
A modelagem tridimensional interessa a vários campos do conhecimento. Esta pesquisa tem como objetivo testar a funcionalidade e aprimorar uma versão beta do software Ester 2.1, sistema de projeção estereográfica para Geologia Estrutural. O projeto envolve, além de buscar recursos para aprimorar e adquirir recursos para o software Estar 2.1, pesquisar recursos para modelagem 3D O teste prático validou o programa até a presente fase, tendo sido introduzidos vários aprimoramentos. O projeto avançou em novos campos de pesquisa que podem ajudar a complementar Ester.
\end{abstract}

Palavras-chave:

Geologia Estrutural, Diagrama Tangente, Modelagem 3D

\section{Introdução}

O ensino de geologia nas universidades brasileiras sofre com o restrito acesso a recursos de modelagem 3D de baixo custo. A Projeção Estereográfica é fundamental na educação em Geociências, ao promover desenvolvimento da autonomia e do potencial do aluno na aquisição de competências de visualização espacial de estruturas. O emprego profissional das redes facilita o entendimento de situações geológicas complexas, cuja interpretação, nas áreas de petróleo e de exploração mineral, pode exigir softwares de modelagem sofisticados e dispendiosos. No campo educacional existem aplicativos menos potentes e de acesso mais restrito (Cruz 2016; Carneiro \& Carvalho 2008, 2012). Projetos anteriores produziram um conjunto de ferramentas computacionais (Mizuno \& Carneiro 2008, Ponte \& Carneiro 2013), que foram testadas nesta pesquisa, buscando investigar o grau de utilidade para fins profissionais e educacionais. Nesta etapa realizou-se a inserção do Diagrama Polar Tangente em Ester 2.1.

Outro objetivo do projeto foi avaliar recursos de modelagem 3D, como: Sketchfab; Visible Geology; e recursos da empresa AutoDesk.

\section{Resultados e Discussão}

O Diagrama Polar Tangente possui funções similares às dos diagramas de Schmidt Lambert e Wulff, cujo uso é mais tradicional. Duas adaptações são feitas na plotagem: 1) O ângulo é contado do centro para as bordas; 2) Planos são ilustrados pelo vetor de caimento.

$\mathrm{O}$ diagrama pode ser utilizado para determinar mergulho aparente (MA) por meio do mergulho real (MR), também é possível reproduzir o MR a partir de dois MAs e, por fim, descobrir a atitude de uma linha de intersecção entre dois planos. O Diagrama é muito prático para distinguir dobras cilíndricas de cônicas, quando existem dados estruturais suficientes. No Diagrama Tangente, a disposição dos vetores de mergulho dos planos dobrados forma um conjunto de pontos, que se dispõem segundo linhas, por aproximação estatística. Dobras cônicas formam uma linha reta, enquanto dobras cônicas assumem a forma de

hipérbole, que pode apresentar concavidade apontada para o centro ou para a borda do diagrama, situações que admitem duas interpretações: antiforma com fechamento da dobra (V) contra o sentido do mergulho da dobra ou sinforma com o $\mathrm{V}$ paralelo ao caimento. No segundo caso o V da antiforma está no mesmo sentido do caimento da dobra ou o $\mathrm{V}$ da sinforma mergulha contra o caimento da dobra. A interpretação das estruturas depende da posição

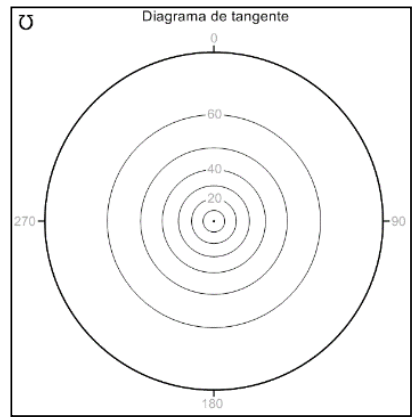

acesso para graduandos.

\section{Conclusões}

O produto final do estudo consistiu na implementação do Diagrama Polar Tangente no software Ester 2.1. Isso permitiu adicionar diversas facilidades ao programa. $\mathrm{Na}$ questão de modelagem 3D, a escolha de uma plataforma de trabalho moderna disponibilizará recursos para que os pesquisadores produzam sólidos tridimensionais com boa referência geológica, como grandes bacias sedimentares.

Bengtson C.A. 1980. Structural uses of tangent diagrams. Geology 8:599-602 Carneiro C.D.R. \& Carvalho A.M.A.de. 2012. Utilização de recursos de ambiente CAD em Geologia Estrutural. Terrae Didatica, 8(2):83-93

Mizuno, T.A.; Carneiro, C.D.R. 2008. Implementação e divulgação de software de projeção estereográfica em sistema operacional 32 bits. In: CONGR. INTERNO INIC. CIENT., 16, Campinas, 2008. Resumos... Campinas: Unicamp. p. 37. [pdfN/844.pdf] (CD-ROM, resumo E0446).

Souza, J.P.P.; Carneiro, C.D.R. 2013. Atualização de programa de projeção estereográfica em ambiente Windows e criação de materiais educacionais a partir dos programas ESTER e TRADE. In: CONGR. INTERNO INIC. CIENT., 21, Campinas, 2013. Resumos... Campinas: UNICAMP. [Resumo E0563] (CDROM, URL: www.prp.rei.unicamp.br/pibic/congressos/xxicongresso/cdrom/ FSCOMMAND/pdfN/563.pdf). 